\title{
Extravasated platelet aggregation contributes to tumor progression via the accumulation of myeloid-derived suppressor cells in gastric cancer with peritoneal metastasis
}

\author{
TAKAHISA YAMAGUCHI, SACHIO FUSHIDA, JUN KINOSHITA, MITSUYOSHI OKAZAKI, \\ SATOKO ISHIKAWA, YOSHINAO OHBATAKE, SHIRO TERAI, KOICHI OKAMOTO, \\ SHINICHI NAKANUMA, ISAMU MAKINO, KEISHI NAKAMURA, TOMOHARU MIYASHITA, \\ HIDEHIRO TAJIMA, HIROYUKI TAKAMURA, ITASU NINOMIYA and TETSUO OHTA \\ Department of Gastroenterological Surgery, Division of Cancer Medicine, \\ Kanazawa University Graduate School of Medical Sciences, Kanazawa, Ishikawa 920-8641, Japan
}

Received November 25, 2019; Accepted May 5, 2020

DOI: $10.3892 / \mathrm{ol} .2020 .11722$

\begin{abstract}
Extravasated platelet aggregation (EPA) serves an important role in the cancer microenvironment during cancer progression, and has been demonstrated to interact with tumor cells in several types of cancer. EPA induces epithelial-mesenchymal transition (EMT) via transforming growth factor- $\beta$, and also recruits immunosuppressive cells, including regulatory $\mathrm{T}$ (Treg) cells and myeloid-derived suppressor cells (MDSCs). However, the role of EPA in gastric cancer with peritoneal metastasis remains unknown. The present study analyzed the association between EPA and prognosis in patients with gastric cancer with peritoneal metastasis. The present study evaluated 62 patients diagnosed with advanced gastric cancer with peritoneal metastasis between 2001 and 2016. EPA, EMT, Treg cells and MDSCs in peritoneal metastatic lesions were detected by immunohistochemical evaluation of CD42b, SNAIL, FOXP3 and CD33, respectively. CD42b expression was observed in $56.5 \%$ (35/62) of peritoneal metastatic lesions. CD42b expression in peritoneal metastatic lesions was associated with poor overall survival compared with lower frequencies (hazard ratio, 2.03; 95\% confidence interval, 1.12-3.69; $\mathrm{P}=0.018$ ). SNAIL, FOXP3 and CD33 expression were not associated with overall survival, but CD33 expression was markedly higher in CD42b-positive patients $(\mathrm{P}=0.022)$. These results indicated that EPA affects immunosuppression by recruiting MDSCs in the tumor microenvironment via the
\end{abstract}

Correspondence to: Dr Sachio Fushida, Department of Gastroenterological Surgery, Division of Cancer Medicine, Kanazawa University Graduate School of Medical Sciences, 13-1 Takara-machi, Kanazawa, Ishikawa 920-8641, Japan E-mail: fushida@staff.kanazawa-u.ac.jp

Key words: gastric cancer, peritoneal metastasis, extravasated platelet aggregation, myeloid-derived suppressor cell, epithelial-mesenchymal transition secretion of soluble factors, resulting in tumor progression. EPA may be a novel therapeutic target for gastric cancer with peritoneal metastasis.

\section{Introduction}

Gastric cancer is one of the most common types of cancer worldwide, and a leading cause of cancer-related deaths (1). Peritoneal metastasis is a frequent recurrent pattern in gastric cancer, and is related to the poor prognosis. Although various treatments including systemic or intraperitoneal chemotherapy for peritoneal metastasis improved, satisfactory outcomes have not been achieved $(2,3)$. There is thus a need for novel treatments in addition to conventional surgery and chemotherapy.

Interactions between cancer cells and tumor stromal cells have a key role in tumor progression, invasion and metastasis. The tumor microenvironment consists of several kinds of cells, such as endothelial cells, cancer-associated fibroblasts (CAFs), and immune cells. We previously reported that activated peritoneal mesothelial cells by transforming growth factor beta 1 (TGF- $\beta 1$ ) caused to tumor invasion and progression (4). Moreover, the intraperitoneal cavity contains a lot of M2 anti-inflammatory phenotype of macrophages, which caused to the development of peritoneal metastasis in gastric cancer (5).

Platelets are the discoid anucleate hematopoietic cells that are responsible for maintaining hemostasis. On the other hand, they have been recognized as key regulators for tumor development and metastasis in several tumors (6-8). Platelet aggregation in the blood vessels protects cancer cells from several stress and immunocompetent cells through the platelet coating around tumor cells. Platelets further promote cancer cell attachment to intravascular endothelial cells, leading to extravasation and the colonization of secondary tumors in new microenvironments (9). However, few studies have examined the role of platelets in primary tumors. We previously found a correlation between extravasated platelet aggregation (EPA) and epithelial-mesenchymal transition (EMT) in breast cancer, and showed that patients with EPA were less responsive to 
neo-adjuvant chemotherapy (10). Furthermore, EPA in primary gastric cancer biopsy specimens was inversely correlated with pathological response to preoperative chemotherapy, and was identified as an independent prognostic factor (11).

Platelets contain a lot of TGF- $\beta$, which they secrete following platelet activation $(12,13)$. TGF- $\beta$ promotes the invasion ability and chemoresistance of tumor cells via the induction of EMT, and also facilitates the induction of immunosuppression by regulatory $\mathrm{T}$ (Treg) cells accumulation into the tumor microenvironment (14). TGF- $\beta$-induced forkhead box (FOX)P3-positive Treg cells have been shown to participate in the maintenance of immunosuppression, and to play critical roles in chemoresistance $(15,16)$. In addition to Treg cells, several studies have demonstrated the importance of myeloid-derived suppressor cells (MDSCs) in tumor-associated immune suppression $(17,18)$. MDSCs may promote the Treg cells infiltration into tumor stroma through the secretion of TGF- $\beta$. Collectively, these findings suggest that EMT, MDSCs, and Treg cell infiltration induced by EPA are key regulators of cancer progression.

In the present study, we investigated the relationship between EPA and prognosis in patients with gastric cancer with peritoneal metastasis by analyzing the expression of CD42b, SNAIL, FOXP3, and CD33 using immunohistochemistry.

\section{Materials and methods}

Patient samples. Sixty-two patients diagnosed with advanced gastric cancer with peritoneal metastasis between 2001 and 2016 were evaluated retrospectively. As inclusion criteria, all patients had collected the peritoneal nodule by surgery included the staging laparoscopy and diagnosed pathologically. Specimens from peritoneal metastatic lesions were collected before chemo/radiotherapy. Patients were excluded for the following reason: Poor general condition or refuse treatment and are unable to treat the gastric cancer.

All procedures were carried out in accordance with the ethical standards of the responsible committees on human experimentation and with the Helsinki Declaration of 1964 and later versions. This study was approved by the Institutional Review Board of Kanazawa University Graduate School of Medical Sciences (study no. 2789). Written informed consent was obtained from all patients.

Evaluation for clinical status. Primary and metastatic lesions were evaluated by gastrointestinal endoscopy and contrast-enhanced computed tomography scan. Peritoneal metastasis was diagnosed by laparoscopy examination or open surgery before chemotherapy, and classified into three categories according to the 15th edition of the General Rules for Gastric Cancer Study of the Japanese Research Society for Gastric Cancer: P1a (greater omentum, lesser omentum, anterior lobe of the transverse colonic membrane, or membrane of the pancreatic surface or spleen), P1b (a few scattered metastases to upper abdominal peritoneum, namely, the parietal peritoneum close to the umbilical side and the visceral peritoneum close to the cranial transverse colon), and P1c (many metastases to middle or lower peritoneum). The ascites level was evaluated by CT and classified into four groups: None, mild (limited the pelvic cavity), moderate (over the pelvic cavity), and severe (all over the abdominal cavity). Univariate analyses of prognostic factors for overall survival (OS) were performed. Patient-related factors included age, sex, and European Cooperative Oncology Group (ECOG) performance status was retrospectively examined. Tumor-related factors were categorized according to the WHO Classification of tumours, 5th edition (19).

Immunohistochemistry. EPA was investigated by immunostaining for CD42b. CD42b (GPIb $\alpha)$ is platelet activation specific marker involved in the process of coagulation (20). All specimens were fixed in $10 \%$ formalin, embedded in paraffin, and cut into the $3-\mu \mathrm{m}$ tissue sections. The specimens were deparaffinized through a graded series of xylene and ethanol. For antigen retrieval, sections were pretreated in $1 \mathrm{mM}$ citrate buffer ( $\mathrm{pH} \mathrm{6.0)}$, and autoclaved for $10 \mathrm{~min}$ at $120^{\circ} \mathrm{C}$. Endogenous peroxidase block was used by peroxidase block solution provided with the EnVision kit for $20 \mathrm{~min}$. After blocking endogenous peroxidase, sections were incubated with $5 \%$ normal goat serum for $20 \mathrm{~min}$ to block nonspecific staining. Sections were subsequently incubated for $2 \mathrm{~h}$ at room temperature with anti-platelet antibody (1:100 dilution, anti-CD42b rabbit monoclonal; Abcam), anti-SNAIL antibody (1:50 dilution, anti-SNAIL rabbit polyclonal antibody, ab180714; Abcam), anti-FOXP3 antibody (1:50 dilution, anti-FOXP3 mouse monoclonal, 236A/E7; Abcam), or anti-CD33 antibody (1:100 dilution, anti-CD33 mouse monoclonal antibody, NCL-L-CD33; Leica Biosystems). After the sections were washed in Phosphate-buffered saline: PBS, immunoreactivity was visualized by EnVision reagent (Dako Co.), and the slides were developed with diaminobenzidine and counterstained with hematoxylin.

Evaluation of immunostaining. Immunostaining sections were evaluated in tumor sites containing cancer cells. To evaluate CD42b expression, immunostained cells were observed in five non-overlapping intratumoral fields at 400x magnification. Cancer cells and immunostained cells in the field were counted, and $\geq 10 \%$ of cancer cells were stained were defined as positive and $<10 \%$ were as negative. For SNAIL evaluation, an immunoreactive score was used by multiplying the staining intensity (0-3) and the stained cell ratio (0-4). Specimens with a score 0 were classified as negative and samples with a score 1-12 were classified as positive (21). FOXP3 cells were evaluated by counting intratumoral fields under high power $(\mathrm{x} 400)$ and the number of FOXP3 positive cells was defined as the mean number per field. The average number of FOXP3 positive cells was calculated, and $\geq 5.5$ was defined as high infiltration and $<5.5$ as low infiltration (22). CD33-positive cell infiltration was evaluated by counting intratumoral fields under high power $(x 400)$. The average number of CD33-positive cells was evaluated: $\geq 11$ was defined as high infiltration and $<11$ as low infiltration (23).

Statistical analysis. Differences in CD42b expression and categorical variables were analyzed using a $\chi^{2}$ test. Overall survival rates were calculated by the Kaplan-Meier method, and the log-rank test was used to compare results between survival times and between subgroups. $\mathrm{P}<0.05$ was taken to indicate statistical significance. All statistical analysis was performed using SPSS v23 (SPSS). 


\section{Results}

Patient and clinicopathological characteristics. The clinicopathological characteristics of the 62 patients at the time of diagnosis of peritoneal metastasis are shown in Table I. The median age was 63 (range, 28-83) years, and 26 patients were men and 36 patients were women. 12 patients had a performance status (PS) $\geq 1$, and the remaining 50 patients had a PS of 0.49 patients had initial and 13 patients had recurrent peritoneal metastasis. Primary gastric cancer was intestinal-type adenocarcinoma in 13 patients and diffuse-type adenocarcinoma in the remaining 49.27 patients had a macroscopic classification of Borrmann type 4 . The $\mathrm{P}$ statuses according to the Japanese Classification of Gastric Carcinoma 15th edition were P1a in 8 cases, P1b in 5 cases, and P1c in 49 cases. The levels of ascites were none in 23, mild in 17 , moderate in 8 , and severe in 14 . Ten patients had other distant metastases, including liver, lung, or lymph node metastasis.

$C D 42 b$ expression in peritoneal metastasis. We investigated CD42b expression as a marker of EPA in 62 patients with peritoneal metastasis. All peritoneal metastasis specimens were collected before chemotherapy. CD42b expression was observed in $56.5 \%(35 / 62)$ of peritoneal metastatic lesions (Fig. 1A and B). EPA was observed around tumor cells and around CAFs (Fig. 1C).

Relationship between CD42b expression and clinicopathological features. The relationships between $\mathrm{CD} 42 \mathrm{~b}$ expression and clinicopathological features, including age, sex, PS, Borrmann type, microscopic type, T stage, N stage, $P$ status, ascites volume, and other distant metastasis are shown in Table II. CD42b expression was clearly related to sex $(\mathrm{P}<0.025)$ and microscopic type $(\mathrm{P}<0.038)$, but not to age, performance status, $\mathrm{T}$ stage, $\mathrm{N}$ stage, $\mathrm{P}$ status, ascites volume, or other distant metastasis.

SNAIL, FOXP3, and CD33 expression. SNAIL expression was mainly confirmed in the nuclei of cancer cells. Positive SNAIL expression was observed in $67.7 \%$ (42/62) of cases (Fig. 1D). There was no relationship between SNAIL and CD42b expression $(\mathrm{P}=0.271$, Table II). Furthermore, there was no association between SNAIL expression and OS (P=0.601, Table III). The Treg cell marker FOXP3 was also confirmed in the nuclei of T cells. High infiltration of FOXP3-positive cells was detected in $16.1 \%$ (23/62) of cases (Fig. 1E). There was no relationship between FOXP3 and CD42b expression ( $\mathrm{P}=0.564$, Table II) or OS $(\mathrm{P}=0.823$, Table III). High infiltration of CD33-positive cells was detected in 59.6\% (37/62) of cases (Fig. 1F), and was clearly correlated with $\mathrm{CD} 42 \mathrm{~b}$ expression $(\mathrm{P}=0.022$, Table II), but not correlated with $\mathrm{OS}(\mathrm{P}=0.111)$.

Relationship between patient characteristics and overall survival. The relationships between clinicopathological features and OS were evaluated by log-rank tests (Table III). OS was clearly lower in patients with P1c (compared to P1a/P1b status), with severe ascites (compared with no or moderate ascites), and in patients with other distant metastases (Table III). OS was not significantly related to age, sex, initial
Table I. Clinical and pathological data of 62 patients with gastric cancer with peritoneal metastasis.

\begin{tabular}{|c|c|}
\hline Characteristics & Value \\
\hline Age, years (median, range) & $63(28-83)$ \\
\hline \multicolumn{2}{|l|}{ Sex, $\mathrm{n}$} \\
\hline Male & 26 \\
\hline Female & 36 \\
\hline \multicolumn{2}{|l|}{ Initial or recurrence, $\mathrm{n}$} \\
\hline Initial & 49 \\
\hline Recurrence & 13 \\
\hline \multicolumn{2}{|l|}{ ECOG performance status, $n$} \\
\hline$\geq 1$ & 12 \\
\hline 0 & 50 \\
\hline \multicolumn{2}{|l|}{ Borrmann macroscopic type, $n$} \\
\hline 1 & 1 \\
\hline 2 & 3 \\
\hline 3 & 26 \\
\hline 4 & 27 \\
\hline 5 & 5 \\
\hline \multicolumn{2}{|c|}{ Differentiation (Lauren classification), $\mathrm{n}$} \\
\hline Intestinal & 13 \\
\hline Diffuse & 49 \\
\hline \multicolumn{2}{|l|}{ Clinical $\mathrm{T}$ stage, $\mathrm{n}$} \\
\hline $\mathrm{T} 1$ & 0 \\
\hline $\mathrm{T} 2$ & 0 \\
\hline $\mathrm{T} 3$ & 11 \\
\hline $\mathrm{T} 4$ & 51 \\
\hline \multicolumn{2}{|l|}{ Clinical $\mathrm{N}$ stage, $\mathrm{n}$} \\
\hline No & 15 \\
\hline N1 & 12 \\
\hline $\mathrm{N} 2$ & 7 \\
\hline N3 & 28 \\
\hline \multicolumn{2}{|l|}{ P status, $n$} \\
\hline P1a & 8 \\
\hline $\mathrm{P} 1 \mathrm{~b}$ & 5 \\
\hline $\mathrm{P} 1 \mathrm{c}$ & 49 \\
\hline \multicolumn{2}{|l|}{ Ascites, $\mathrm{n}$} \\
\hline None & 23 \\
\hline Mild & 17 \\
\hline Moderate & 8 \\
\hline Severe & 14 \\
\hline \multicolumn{2}{|l|}{ Other distant metastasis, $\mathrm{n}$} \\
\hline Negative & 52 \\
\hline Positive & 10 \\
\hline
\end{tabular}

P1a, greater omentum, lesser omentum anterior lobe of the transverse colonic membrane, or membrane of the pancreatic surface or spleen; $\mathrm{P} 1 \mathrm{~b}$, a few scattered metastases to upper abdominal peritoneum, namely, the parietal peritoneum close to the umbilical side and the visceral peritoneum close to the cranial transverse colon; P1c, many metastases to middle or lower peritoneum; Ascites mild, limited to the pelvic cavity; Ascites moderate, over the pelvic cavity; Ascites severe, all over the abdominal cavity; ECOG, European Cooperative Oncology Group. 
A

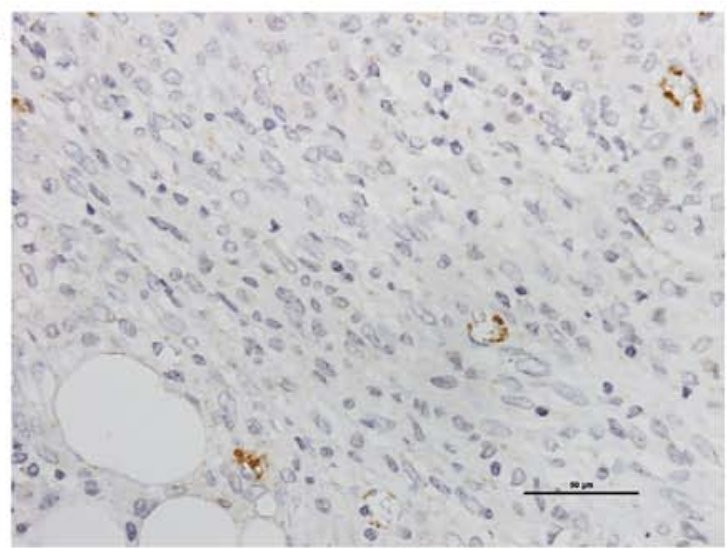

C

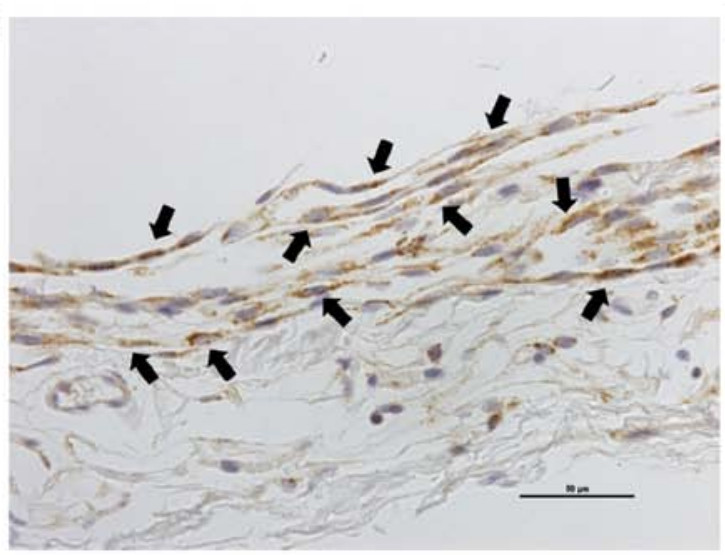

E

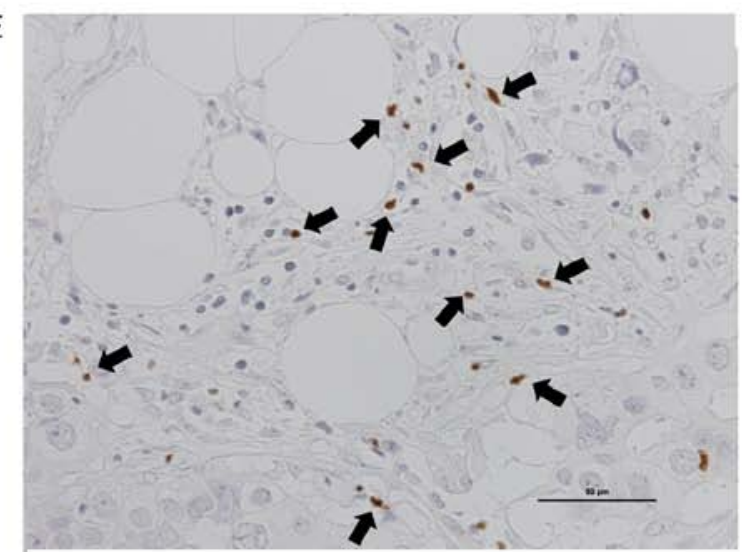

B

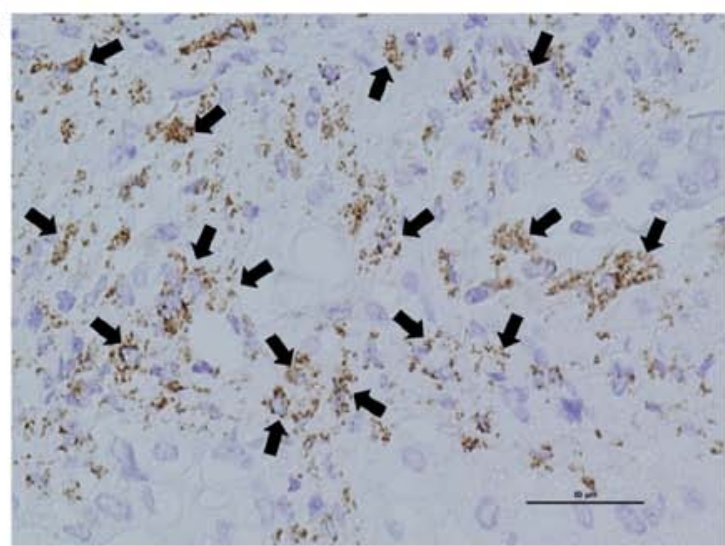

D

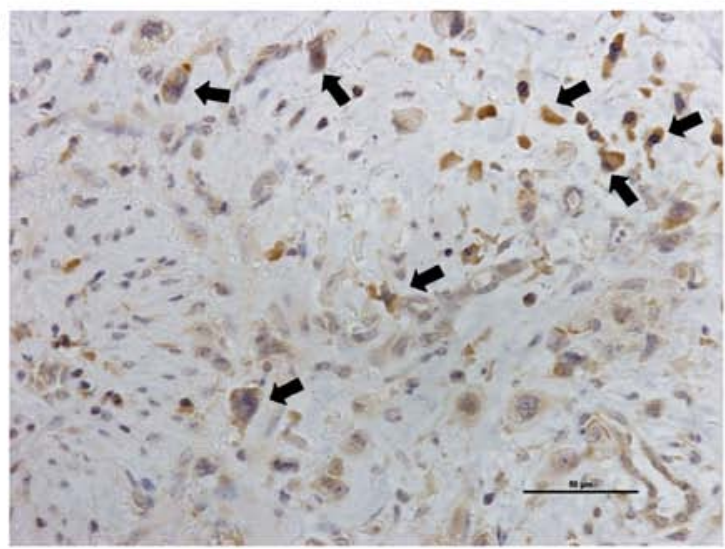

$\mathrm{F}$

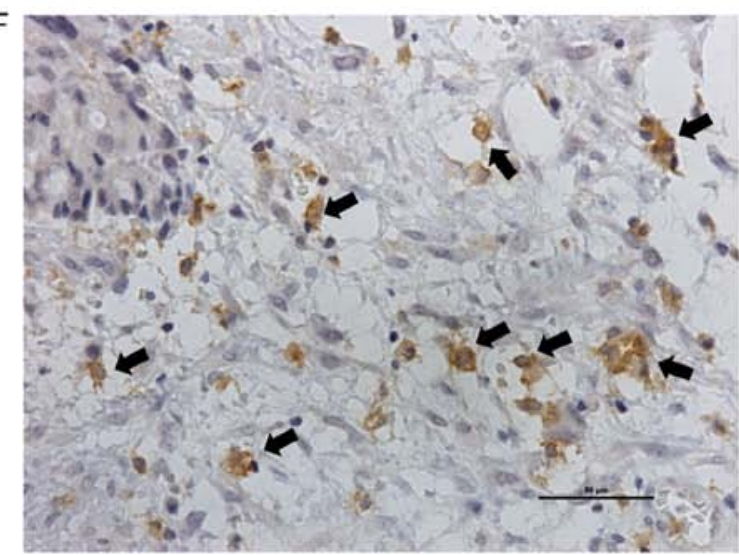

Figure 1. Representative immunostaining images of peritoneal metastasis. (A) Cancer cells and immunostained cells in the field were counted. Positive, $\geq 10 \%$ of cancer cells were stained; negative, $<10 \%$ of cancer cells were stained. Negative expression of CD42b. (B) CD42b-positive platelets (black arrows) were detected around tumor cells (>10\%). (C) Platelet aggregation (CD42b expression) was observed around the CAFs (black arrows). (D) SNAIL expression was mainly confirmed in the nuclei of cancer cells (black arrows). (E) The regulatory $\mathrm{T}$ cell marker forkhead box P3 was also identified in the nuclei of $\mathrm{T}$ cells (black arrow). (F) CD33 expression was observed in cancer stroma (black arrows). Scale bar, $50 \mu \mathrm{m}$. CAFs, cancer-associated fibroblasts.

or recurrent peritoneal metastasis, ECOG PS, Borrmann type, or microscopic type.

Survival curves according to CD42b, SNAIL, FOXP3, and CD33 expression. OS curves for gastric cancer with peritoneal metastasis are shown in Fig. 2. Median OS for CD42b-positive patients were 13.6 months compared with 28.4 for CD42b-negative patients (hazard ratio $2.03,95 \%$ confidence interval 1.12-3.69, $\mathrm{P}=0.018)$. In contrast, SNAIL, FOXP3, and CD33 expression in peritoneal metastatic lesions were not significantly related to OS (Fig. 2B-D).

\section{Discussion}

We detected CD42b expression as a marker of EPA in $56.4 \%$ of peritoneal metastases for patients with gastric cancer in the current study, and clarified that it was a poor prognosis factor. All patients were diagnosed as Stage IV gastric cancer with peritoneal metastasis. In our previous study, there were no significant association between CD42b expression and clinical stage (11). Generally, tumor stroma contains fibroblasts which express the p-selectin, and tend to aggregate the platelets (Fig. 1C). In this study, we evaluated the gastric cancer cells and 
Table II. Association between CD42b expression and the clinicopathological characteristics of patients with gastric cancer with peritoneal metastasis.

\begin{tabular}{|c|c|c|c|}
\hline Variables & CD42(-), n (n=27) & $\mathrm{CD} 42(+), \mathrm{n}(\mathrm{n}=35)$ & P-value \\
\hline Age, years & & & 0.639 \\
\hline$\geq 70$ & 7 & 10 & \\
\hline$<70$ & 20 & 25 & \\
\hline Sex & & & 0.025 \\
\hline Male & 7 & 19 & \\
\hline Female & 20 & 16 & \\
\hline Initial or recurrence & & & 0.697 \\
\hline Initial & 21 & 28 & \\
\hline Recurrence & 6 & 7 & \\
\hline ECOG performance status & & & 0.425 \\
\hline 0 & 24 & 26 & \\
\hline$\geq 1$ & 3 & 9 & \\
\hline Borrmann macroscopic type & & & 0.373 \\
\hline Type 4 & 10 & 17 & \\
\hline Not & 17 & 18 & \\
\hline Microscopic & & & 0.038 \\
\hline Intestinal & 9 & 4 & \\
\hline Diffuse & 18 & 31 & \\
\hline Clinical T stage & & & 0.678 \\
\hline $2-3$ & 5 & 6 & \\
\hline 4 & 22 & 29 & \\
\hline Clinical N stage & & & 0.405 \\
\hline $0-2$ & 16 & 18 & \\
\hline 3 & 11 & 17 & \\
\hline P status & & & 0.228 \\
\hline $1 \mathrm{a}, 1 \mathrm{~b}$ & 8 & 5 & \\
\hline $1 \mathrm{c}$ & 19 & 30 & \\
\hline Ascites & & & 0.084 \\
\hline None-Moderate & 23 & 25 & \\
\hline Severe & 4 & 10 & \\
\hline Other distant metastasis & & & 0.296 \\
\hline Negative & 24 & 28 & \\
\hline Positive & 3 & 7 & \\
\hline SNAIL expression & & & 0.271 \\
\hline Negative & 11 & 9 & \\
\hline Positive & 16 & 26 & \\
\hline FOXP3 infiltration & & & 0.564 \\
\hline Low & 18 & 21 & \\
\hline High & 9 & 14 & \\
\hline CD33 infiltration & & & 0.022 \\
\hline Low & 17 & 8 & \\
\hline High & 10 & 27 & \\
\hline
\end{tabular}

ECOG, European Cooperative Oncology Group; FOXP3, forkhead box P3.

platelet aggregation (Fig. 1B), and did not evaluate the platelets around the fibroblasts. Platelets play an important role in the tumor microenvironment during cancer development, and have been shown to interact with tumor cells. Mikami et al (24) investigated that platelets facilitated the gastric cancer cells growth and that this growth was disturbed by antiplatelet 
Table III. Univariate analyses of clinicopathological parameters associated with overall survival in patients with gastric cancer with peritoneal metastasis.

\begin{tabular}{|c|c|c|c|c|}
\hline Variables & Odds ratio & $95 \% \mathrm{CI}$ & No. & P-value \\
\hline Age, years & & & & 0.287 \\
\hline$\geq 70$ & 1.519 & $0.700-3.293$ & 17 & \\
\hline$<70$ & & & 45 & \\
\hline Sex & & & & 0.522 \\
\hline Male & 1.211 & $0.673-2.180$ & 26 & \\
\hline Female & & & 36 & \\
\hline Initial or recurrence & & & & 0.286 \\
\hline Initial & 1.466 & $0.723-2.972$ & 49 & \\
\hline Recurrence & & & 13 & \\
\hline ECOG performance status & & & & 0.331 \\
\hline 0 & 1.556 & $0.838-2.888$ & 50 & \\
\hline$\geq 1$ & & & 12 & \\
\hline Borrmann macroscopic type & & & & 0.736 \\
\hline Type4 & 0.905 & $0.506-1.619$ & 27 & \\
\hline Not & & & 35 & \\
\hline Microscopic & & & & 0.535 \\
\hline Intestinal & 0.811 & $0.418-1.575$ & 13 & \\
\hline Diffuse & & & 49 & \\
\hline P status & & & & 0.022 \\
\hline $1 \mathrm{a}, 1 \mathrm{~b}$ & 2.242 & $1.070-4.698$ & 13 & \\
\hline $1 \mathrm{c}$ & & & 49 & \\
\hline Ascites & & & & 0.009 \\
\hline None-Moderate & 2.555 & $1.325-4.928$ & 48 & \\
\hline Severe & & & 14 & \\
\hline Other distant metastasis & & & & 0.043 \\
\hline Negative & 2.231 & $1.006-4.948$ & 10 & \\
\hline Positive & & & 52 & \\
\hline CD42b expression & & & & 0.018 \\
\hline Negative & 2.029 & $1.115-3.690$ & 27 & \\
\hline Positive & & & 35 & \\
\hline SNAIL expression & & & & 0.606 \\
\hline Negative & 0.85 & $0.459-1.576$ & 20 & \\
\hline Positive & & & 42 & \\
\hline FOXP3 infiltration & & & & 0.823 \\
\hline Low & 1.073 & $0.580-1.983$ & 39 & \\
\hline High & & & 23 & \\
\hline CD33 infiltration & & & & 0.111 \\
\hline Low & 1.712 & $0.878-3.341$ & 25 & \\
\hline High & & & 37 & \\
\hline
\end{tabular}

P-values were obtained using a log-rank test. ECOG, European Cooperative Oncology Group; FOXP3, forkhead box P3.

drugs in vitro and in vivo. Platelets contain a large amount of growth factors, such as TGF- $\beta$, platelet-derived growth factor, epidermal growth factor, vascular endothelial growth factor (VEGF), sphingosine 1-phospate, and basic fibroblastic growth factor within the $\alpha$-granules that are secreted following platelet activation (25). Han et al (26) reported that platelet pellet $\left(10^{6}\right.$ platelets $)$ from breast cancer patients contained higher TGF- $\beta 1$ level (median $15.3 \mathrm{ng} / \mathrm{ml}$ ) than control group (median $4.3 \mathrm{ng} / \mathrm{ml}$ ). These growth factors affect the tumor progression, angiogenesis, invasion, EMT, and metastasis, not only in the blood vessels but also in the tumor stroma. Previous reports have suggested a correlation between EPA 
A

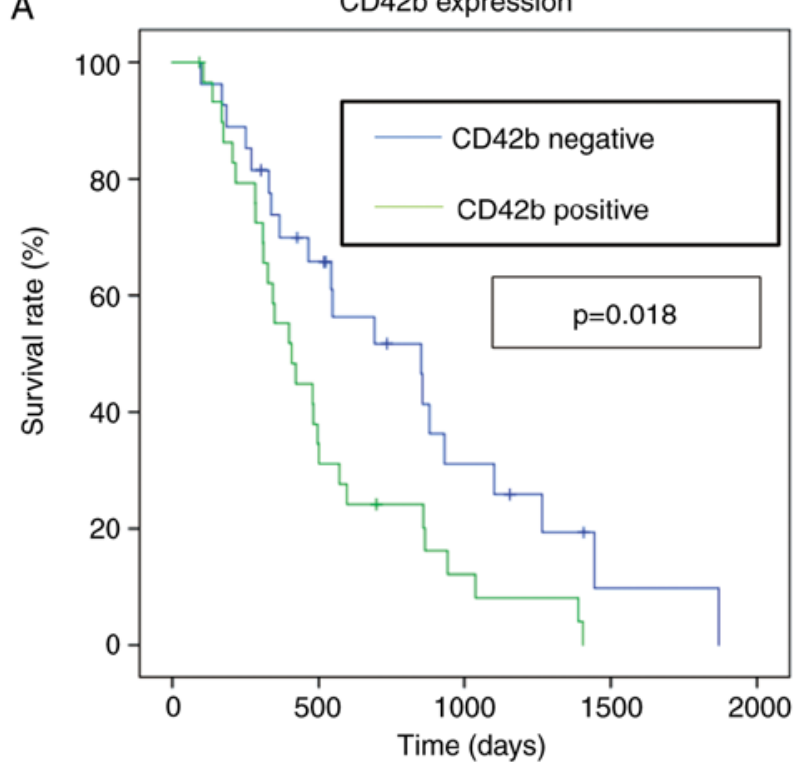

C

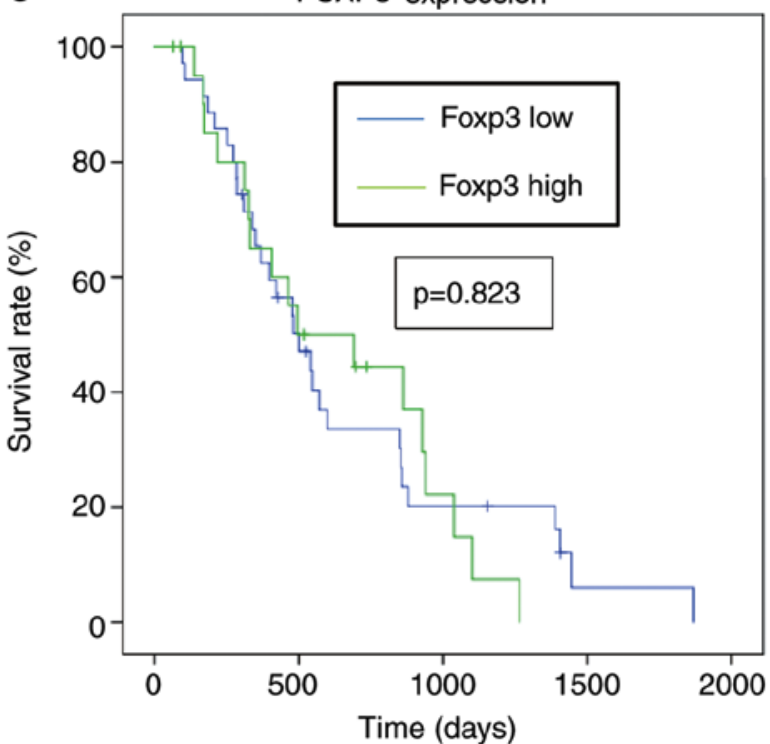

B

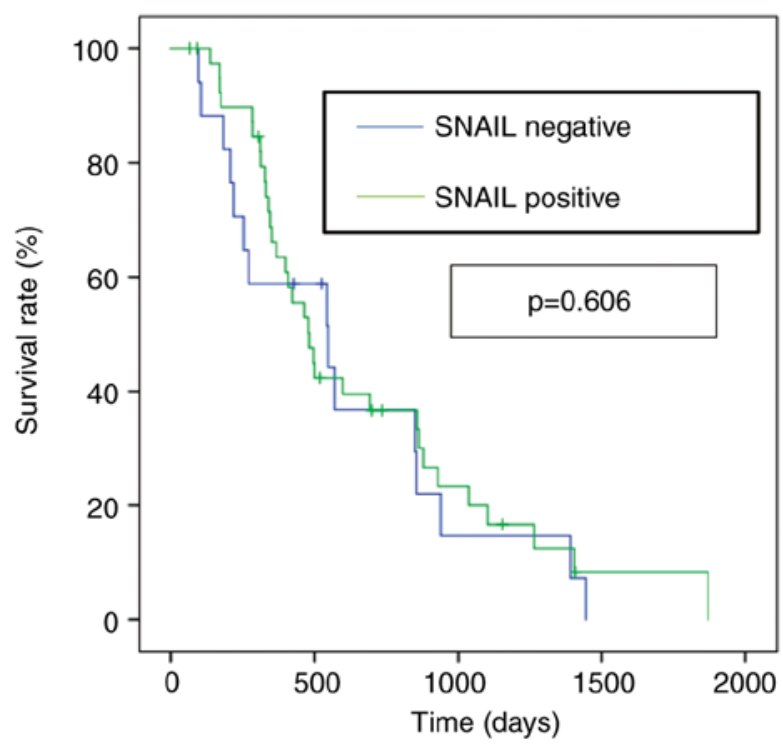

D

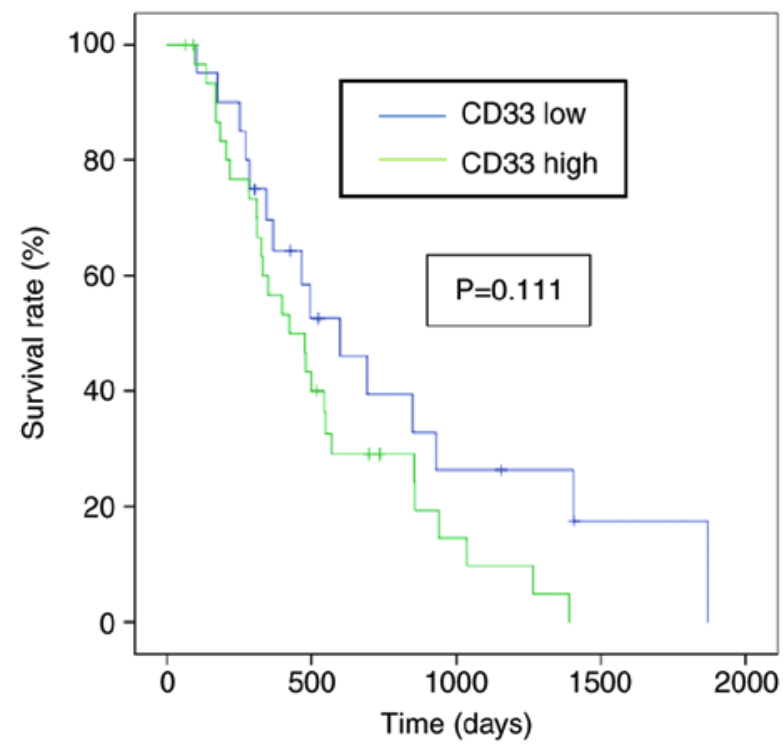

Figure 2. OS curves. (A) Median OS for CD42b-positive patients was 13.6 months compared with 28.4 months for CD42b-negative patients (hazard ratio, 2.03; 95\% confidence interval, 1.12-3.69; $\mathrm{P}=0.018$ ) (B) OS according to SNAIL expression ( $\mathrm{P}=0.606$; log-rank test). (C) OS according to FOXP3 expression. (D) OS according to CD33 expression. SNAIL ( $\mathrm{P}=0.606)$, FOXP3 $(\mathrm{P}=0.823)$ and $\mathrm{CD} 33(\mathrm{P}=0.111)$ expression in peritoneal metastatic lesions were not significantly associated with OS. FOXP3, forkhead box P3; OS, overall survival.

and EMT (10); however our data found no association between expression of the EMT marker SNAIL and EPA. This apparent discrepancy could be explained by differences in the tumor microenvironment between primary lesions and metastatic lesions, given that various stromal cells, including CAFs, human peritoneal mesothelial cells, mesenchymal stem cells, and M2 macrophages are present in the peritoneal metastasis environment and affect the EMT in tumor cells (5,27-29).

CD33 and CD11b are considered as basic markers of MDSCs. Yu et al (30), also reported that most CD33-positive cells in primary solid tumors were MDSCs. The current results found a close relationship between CD42b expression and CD33 infiltration in peritoneal metastasis. MDSCs play a pivotal role in tumor-related immunosuppression, and are recruited by several factors, including TGF- $\beta$, VEGF, and matrix metalloproteinase 9 , which are also secreted by platelets (31-33).

MDSCs promote tumor growth by shaping immunosuppressive responses towards tumor tolerance, and also by supporting several processes necessary for neoplastic progression, such as tumor angiogenesis, cancer stemness, and metastasis dissemination. Our findings thus showed that the presence of EPA in the tumor microenvironment may induce the recruitment of MDSCs, resulting in tumor progression.

A large volume of ascites fluid was associated with a worse prognosis in this current study. However there was no significant correlation between platelet aggregation and ascitic fluid volume, there was a tendency for the volume of ascitic fluid to be higher in CD42b-positive cases. We previously reported 
a close relationship between ascites volume and VEGF levels in the peritoneal cavity, with high levels of VEGF being correlated with a poor prognosis (34). Expression for VEGF was also detected in $>70 \%$ of peritoneal metastases. These results indicate that VEGF secretion by cancer cells and platelets promote tumor development by inducing the angiogenesis in the peritoneal cavity.

VEGF is important for inducing an immunosuppressive microenvironment in several tumors via MDSCs (35). Horikawa et al (36) reported that VEGF in ovarian cancer with peritoneal metastatic lesions inhibited immune functions through MDSCs. Intratumoral MDSCs have also been shown to express VEGF receptor 2, and VEGF/VEGF receptor 2 signaling directly promoted MDSC differentiation and tumor infiltration (37,38). Collectively, these data suggest that MDSCs induced by tumor- and platelet-derived VEGF signaling play important roles in tumor immune evasion.

The present study had several limitations. First, regarding possible heterogeneity of tumor characteristics; the pathology of gastric cancer with peritoneal metastasis is complicated, and it is difficult to prove if a small biopsy sample is characteristic of metastatic lesion. Second, it is not sufficient to identify the MDSC by the CD33 staining, though the MDSC marker is lack of defined it. Furthermore, the accumulation of MDSCs by platelets is consideration in this study, it is necessary to study in vitro and in vivo experiments. However, there were few reports on the immune environment in gastric cancer with peritoneal metastasis, our results are important. Third, this investigation was conducted at a single institution, retrospective study, with a relatively small sample size. However, it is difficult to collect peritoneal metastatic tissue because gastric cancer patients with peritoneal metastasis generally do not undergo surgery. These factors should therefore be taken into account, and further, prospective, multi-center studies are needed to confirm the results before they can be generalized to daily clinical work.

In conclusion, the results of the present study suggest that EPA is associated with a poor prognosis in gastric cancer patients with peritoneal metastasis. EPA may not only increase tumor malignancy by secreting soluble factors such as platelet-derived growth factor, basic fibroblastic growth factor, and VEGF, but may also affect immunosuppression through the infiltration of MDSCs into the tumor microenvironment. These data indicate that EPA may represent a novel therapeutic target in gastric cancer with peritoneal metastasis.

\section{Acknowledgements}

The authors would like to thank Dr Susan Furness for editing a draft of this manuscript.

\section{Funding}

No funding was received.

\section{Availability of data and materials}

The datasets used and/or analyzed during the present study are available from the corresponding author on reasonable request.

\section{Authors' contributions}

TY and SF conceived the study. TY performed the experiments, analyzed data and wrote the manuscript. SF analyzed and interpreted the data. JK, MO, SI, YO, ST, KO, SN and IM were involved in conception and design. KN, TM, HTaj, HTak, IN and TO were involved in analysis and interpretation of data. SF contributed to manuscript writing and revision. All authors read and approved the final manuscript.

\section{Ethics approval and consent to participate}

All procedures were carried out in accordance with the ethical standards of the responsible committees on human experimentation and with the Helsinki Declaration of 1964 and later versions. This study was approved by the Institutional Review Board of Kanazawa University Graduate School of Medical Sciences (study number 2789). Written informed consent was obtained from all patients.

\section{Patient consent for publication}

Not applicable.

\section{Competing interests}

The authors declare that they have no competing interests.

\section{References}

1. Bray F, Ferlay J, Soerjomataram I, Siegel RL, Torre LA and Jemal A: Global cancer statistics 2018: GLOBOCAN estimates of incidence and mortality worldwide for 36 cancers in 185 countries. CA Cancer J Clin 68: 394-424, 2018.

2. Fushida S, Kinoshita J, Yagi Y, Funaki H, Kinami S, Ninomiya I, Fujimura T, Nishimura G, Kayahara M and Ohta T: Dual anti-cancer effects of weekly intraperitoneal docetaxel in treatment of advanced gastric cancer patients with peritoneal carcinomatosis: A feasibility and pharmacokinetic study. Oncol Rep 19: 1305-1310, 2008.

3. Fushida S, Kinoshita J, Kaji M, Hirono Y, Goda F, Yagi Y, Oyama K, Sudo Y, Watanabe Y and Fujimura T; Society for Study of Peritoneal Carcinomatosis in Gastric Cancer: Phase I/II study of intraperitoneal docetaxel plus S-1 for the gastric cancer patients with peritoneal carcinomatosis. Cancer Chemother Pharmacol 71: 1265-1272, 2013.

4. Tsukada T, Fushida S, Harada S, Yagi Y, Kinoshita J, Oyama K, Tajima H, Fujita H, Ninomiya I, Fujimura T and Ohta T: The role of human peritoneal mesothelial cells in the fibrosis and progression of gastric cancer. Int J Oncol 41: 476-482, 2012.

5. Yamaguchi T, Fushida S, Yamamoto Y, Tsukada T, Kinoshita J, Oyama K, Miyashita T, Tajima H, Ninomiya I, Munesue S, et al: Tumor-associated macrophages of the M2 phenotype contribute to progression in gastric cancer with peritoneal dissemination. Gastric Cancer 19: 1052-1065, 2016.

6. Lal I, Dittus K and Holmes CE: Platelets, coagulation and fibrinolysis in breast cancer progression. Breast Cancer Res 15: 207, 2013.

7. Takagi S, Takemoto A, Takami M, Oh-Hara T and Fujita N: Platelets promote osteosarcoma cell growth through activation of the platelet-derived growth factor receptor-Akt signaling axis. Cancer Sci 105: 983-988, 2014.

8. Bambace NM and Holmes CE: The platelet contribution to cancer progression. J Thromb Haemost 9: 237-249, 2011.

9. Ludwig RJ, Boehme B, Podda M, Henschler R, jager E, Tandi C, Boehncke WH, Zollner TM, Kaufmann R and Gille J: Endothelial P-selectin as a target of heparin action in experimental melanoma lung metastasis. Cancer Res 64: 2743-2750, 2004.

10. Ihsikawa S, Miyashita T, Inokuchi M, Hayashi H, Oyama K, Tajima H, Takamura H, Ninomiya I, Ahmed AK, Harman JW, et al: Platelets surrounding primary tumor cells are related to chemoresistance. Oncol Rep 36: 787-794, 2016. 
11. Saito H, Fushida S, Miyashita T, Oyama K, Yamaguchi T, Tsukada T, Kinoshita J, Tajima H, Ninomiya I and Ohta T: Potential of extravasated platelet aggregation as a surrogate marker for overall survival in patients with advanced gastric cancer treated with preoperative docetaxel, cisplatin and S-1: A retrospective observational study. BMC Cancer 17: 294, 2017.

12. Assoian RK, Komoriya A, Meyers CA, Miller DM and Sporn MB: Transforming growth factor-beta in human platelets. Identification of a major storage site, purification, and characterization. J Biol Chem 258: 7155-7160, 1983.

13. Labelle M, Begum S and Hynes RO: Direct signaling between platelets and cancer cells induces an epithelial-mesenchymal-like transition and promotes metastasis. Cancer Cell 20: 576-590, 2011.

14. Liu H, Zhang T, Ye J, Li H, Huang J, Li X, Wu B, Huang X and Hou J: Tumor-infiltrating lymphocytes predict response to chemotherapy in patients with advance non-small cell lung cancer. Cancer Immunol Immunother 61: 1849-1856, 2012.

15. Nishikawa $\mathrm{H}$ and Sakaguchi S: Regulatory $\mathrm{T}$ cells in tumor immunity. Int J Cancer 127: 759-767, 2010.

16. Winkler I, Wilczynska B, Bojarska-Junak A, Gogacz M, Adamiak A, Postawski K, Darmochwal-Kolarz D, Rechberger T and Tabarkiewicz J: Regulatory T lymphocytes and transforming growth factor beta in epithelial ovarian tumors-prognostic significance. J Ovarian Res 8: 39, 2015.

17. Kusmartsev S and Gabrilovich DI: Role of immature myeloid cells in mechanisms of immune evasion in cancer. Cancer Immunol Immunother 55: 237-245, 2006.

18. Talmadge JE: Pathways mediating the expansion and immunosuppressive activity of myeloid-derived suppressor cells and their relevance to cancer therapy. Clin Cancer Res 13(18 Pt 1): 5243-5248, 2007.

19. World Health Organization: Classification of tumours. Vol. 1. 5th edition. World Health Organization, Geneva, p54-64, 2019.

20. Xu XR, Carrim N, Neves MA, McKeown T, Stratton TW Coelho RM, Lei X, Chen P, Xu J, Dai X, et al: Platelets and platelet adhesion molecules: Novel mechanisms of thrombosis and anti-thrombotic therapies. Thromb J 14 (Suppl 1): S29, 2016

21. Keck B, Wach S, Goebell PJ, Kunath F, Bertz S, Lehmann J, Stöckle M, Taubert H, Wullich B and Hartmann A: SNAI1 protein expression is an independent negative prognosticator in muscle-invasive bladder cancer. Ann Surg Oncol 20: 3669-3674, 2013.

22. Oda N, Shimazu K, Naoi Y, Morimoto K, Shimomura A, Shimoda M, Kagara N, Maruyama N, Kim SJ and Noguchi S: Intratumoral regulatory $\mathrm{T}$ cells as an independent predictive factor for pathological complete response to neoadjuvant paclitaxel followed by 5-FU/epirubicin/cyclophosphamide in breast cancer patients. Breast Cancer Res Treat 136: 107-116, 2012.

23. Dong J, Li J, Liu SM, Feng XY, Chen S, Chen YB and Zhang XS: CD33+/p-STAT1+ double-positive cell as a prognostic factor for stage IIIa gastric cancer. Med Oncol 30: 442, 2013.

24. Mikami J, Kurokawa Y, Takahashi T, Miyazaki Y, Yamasaki M, Miyata H, Nakajima K, Takiguchi S, Mori M and Doki Y: Antitumor effect of antiplatelet agents in gastric cancer cells: An in vivo and in vitro study. Gastric Cancer 19: 817-826, 2016.

25. Stegner D, Dutting S and Nieswandt M: Mechanistic explanation for platelet contribution to cancer metastasis. Thromb Res 133 (Suppl 2): S149-S157, 2014.

26. Han H, Cao FL, Wang BZ, Mu XR, Li GY and Wang XW: Expression of angiogenesis regulatory proteins and epithelial-mesenchymal transition factors in platelets of the breast cancer patients. ScientificWorldJournal 2014: 878209, 2014.
27. Hong HN, Won YJ, Shim JH, Kim HJ, Han SH, Kim BS and Kim HS: Cancer-associated fibroblasts promote gastric tumorigenesis through EphA2 activation in a ligand-independent manner. J Cancer Res Clin Oncol 144: 1649-1663, 2018.

28. Sun L, Wang Q, Chen B, Zhao Y, Shen B, Wang X, Zhu M, Li Z, Zhao X, Xu C, et al: Human gastric cancer mesenchymal stem cell-derived IL15 contributes to tumor cell epithelial-mesenchymal transition via upregulation tregs ratio and PD-1 expression in CD4_T cell. Stem Cells Dev 27: 1203-1214, 2018.

29. Yan Y, Zhang J, Li JH, Liu X, Wang JZ, Qu HY, Wang JS and Duan XY: High tumor-associated macrophages infiltration is associated with poor prognosis and may contribute to the phenomenon of epithelial-mesenchymal transition in gastric cancer. Onco Targets Ther 9: 3975-3983, 2016.

30. Yu J, Wang Y, Yan F, Zhang P, Li H, Zhao H, Yan C, Yan F and Ren X: Noncanonical NF-kB activation mediates stat3-stimulated IDO upregulation in myeloid-derived suppressor cells in breast cancer. J immunol 193: 2574-2586, 2014.

31. Gabrilovich D, Ishida T, Oyama T, Ran S, Kravtsov V, Nadaf S and Carbone DP: Vascular endothelial growth factor inhibits the development of dendritic cells and dramatically affects the differentiation of multiple hematopoietic lineages in vivo. Blood 92: 4150-4166, 1998

32. Yang L and Moses HL: Transforming growth factor beta: Tumor suppressor or promoter? Are host immune cells the answer? Cancer Res 68: 9107-9111, 2008.

33. Melani C, Sangaletti S, Barazzetta FM, Werb Z and Colombo MP: Amino-bisphosphonate-mediated MMP-9 inhibition breaks the tumor-bone marrow axis responsible for myeloid-derived suppressor cell expansion and macrophage infiltration in tumor stroma. Cancer Res 67: 11438-11446, 2007.

34. Fushida S, Oyama K, Kinoshita J, Yagi Y, Okamoto K, Tajima H, Ninomiya I, Fujimura T and Ohta T: VEGF is a target molecule for peritoneal metastasis and malignant ascites in gastric cancer: Prognostic significance of VEGF in ascites and efficacy of anti-VEGF monoclonal antibody. Onco Targets Ther 6: 1445-1451, 2013.

35. Voron T, Marcheteau E, Pernot S, Colussi O, Tartour E, Taieb J and Terme M: Control of the immune response by pro-angiogenic factors. Front Oncol 4: 70, 2014.

36. Horikawa N, Abiko K, Matsumura N, Hamanishi J, Baba T, Yamaguchi K, Yoshioka Y, Koshiyama M and Konishi I: Expression of vascular endothelial growth factor in ovarian cancer inhibits tumor immunity through the accumulation of myeloid-derived suppressor cells. Clin Cancer Res 23: 587-599, 2017.

37. Yang J, Yan J and Liu B: Targeting VEGF/VEGFR to modulate antitumor immunity. Front Immunol 9: 978, 2018.

38. Secondini C, Coquoz O, Spagnuolo L, Spinetti T, Peyvandi S, Ciarloni L, Botta F, Bourquin C and Rüegg C: Arginase inhibition suppresses lung metastasis in the 4T1 breast cancer model independently of the immunomodulatory and anti-metastatic effects of VEGFR-2 blockade. Oncoimmunology 6: e1316437, 2017.

This work is licensed under a Creative Commons

Attribution-NonCommercial-NoDerivatives 4.0 International (CC BY-NC-ND 4.0) License. 